\title{
UNA FUENTE PARA EL ESTUDIO DE LAS LUCHAS NOBILIARIAS EN LA GALICIA DEL SIGLO XV
}

\author{
POR \\ ANGEL RODRIGUEZ GONZALEZ
}

AUNQUE la situación de los territorios que formaban la monarquía castellana del siglo Xv no ofrece, ni mucho menos, un cuadro de pacífica convivencia, ha quedado estereotipada como tierra de revuelta permanente el reino de Galicia, y así se recoge en todos los textos cronísticos de la Baja Edad Media española. Sin ser una excepción, hemos de admitir, sin embargo, que tal estado responde a una realidad, y así se pone de manifiesto en una crónica gallega que, a pesar de su importancia, no ha sido recogida en la historia de la historiografía española. Nos referimos a Vasco de Aponte, autor de una Relación de algunas Casas y Linages del Reino de Galicia, que se escribió en la primera mitad del siglo xvI. Su autor fue escudero de la Casa de Andrade y su obra adolece de imprecisiones cronológicas, pero, como se ha dicho de él, fue un magnífico historiador «porque ni siquiera pretendió serlo».

En la citada Relación se hace una pormenorizada exposición de los sucesos ocurridos entre los representantes más destacados de la nobleza gallega antes y después de la guerra hermandina, y en ella nos presenta un esquema de la táctica seguida por los caballeros gallegos en sus luchas, armas defensivas y ofensivas, referencias a fortalezas, etc.

De su lectura llama la atención, en primer lugar, el gran aporte de tácticas y añagazas utilizadas en los enfrentamientos. Así, tenemos el caso de Ruy Sánchez de Moscoso, que, perseguido por las fuerzas del arzobispo de Santiago, se refugia en el castro de Angrois, cercano a la ciudad, y aprovechando la estrechez de la boca del mismo y para evitar el ataque de la caballería enemiga, sacrifica dos cabalgaduras, que, colocadas en el camino de entrada, contuvieron la embestida de aquélla por la repugnancia que sienten los animales ante un cadáver de su misma especie: «nunca les escapara sino por dos bestias muertas que les echó en la boca del castro para espantar los caballos». Hay también el uso de lo que podríamos llamar táctica psicológica de provocar al enemigo para hacerle perder su situación ventajosa, tal es el caso de Esteban de Junqueras tratando de sacar a García Martín de los muros de la fortaleza de Altamira, dirigién- 
dole palabras provocadoras: « Ah traidor, a mis manos has de morir! El diablo te trajo aquí.» A lo cual, el segundo contestó: « ‘Oh cornudo, traidor, no has acá de entrar como piensas, que hombres estamos dentro que te sabremos tornar y a toda tu compañía! » Esta provocación no sólo era utilizada por los caudillos de la hueste, sino que en ocasiones adquiere aspecto colectivo tanto más manifiesto cuando se trata de pelear con individuos de otra nacionalidad. Es lo ocurrido en el cerco del castillo de Sobroso. Este castillo estaba sitiado por Pedro Alvarez de Sotomayor con un ejército de sesenta hombres de a caballo y mil peones. Muchos de ellos eran portugueses. Acudieron a socorrer a los del castillo el arzobispo de Santiago, Alonso de Fonseca, y el conde de Monterrey con trescientas lanzas y cinco o seis mil peones. Pertrechado Pedro de Sotomayor, bien avituallado de abundancia de víveres, construida una barrera y un gran palancote, se decidía a esperar que el ejército enemigo tuviese que retirarse por la falta de provisiones sin conseguir su objetivo. Había, sin embargo, el temor de que sus hombres, al sentirse entre dos ejércitos enemigos, se desmoralizaran, y así procuró mantener la moral diciéndoles que el ejército que tenían enfrente era el más escogido de los que pudieran juntarse en Galicia, que, sin embargo, podría resistírsele y precaviéndoles que al no poder vencerles procuraría ya «que por fuerza no nos han de entrar farnos han muchos engaños diciéndonos diez mil deshonras para provocarnos que salgamos a ellos, mas nosotros estémonos quedos y ansí porque son ellos muchos y tienen poca vitualla, aunque les pese se han de ir, y nosotros saldremos con nuestra intención y ganaremos la mayor honra del mundo». Y no se equivocó el astuto Pedro Madruga, pues temerosos el arzobispo y el conde de Monterrey de que acudiesen más portugueses, por estar cercanos al país vecino, procuraron hacer salir a los enemigos y llevarlos hacia dos celadas que les tenían preparadas. La retaguardia insultaba a los portugueses, llamándoles «sebosos, cabrones, que no eran buenos sino para comer bofes de vaca». Reaccionaron los portugueses, arremetiendo contra los que les insultaban al par que proferían gritos de: « ¿Esperad, ladrones, gallegos, páparos, torrezneros! "Viendo aquello, el de Sotomayor les decía a los gallegos que quedaron con él que no abandonasen y que dejasen «ir a aquellos locos». Así ocurrió y pudieron ver cómo la prudencia de su jefe les había evitado sufrir la suerte de los portugueses, que volvieron maltrechos después de perder entre muertos y heridos ciento cincuenta hombres.

Es del mismo Pedro Alvarez de Sotomayor del que cuenta Vasco de Aponte, que no disimula su admiración por él, el sistema de coacción que utilizó, aunque fracasó en su intento, para que le entregasen el castillo de Sobroso, propiedad de García de Sarmiento, entonces prisionero del demandante. El castillo estaba defendido por un capitán cuñado de Sar- 
Gladius, Vol. especial (1988), pp. 193-196 Actas del I Simposio Nacional

miento. Se pretendía un cambio: el castillo por el prisionero. La escena está descrita con tintes de gran efecto teatral, pues llevado García Sarmiento cerca de la puerta de la fortaleza, «se ponía un repostero, y sobre él ponía al prisionero y decía a los del castillo: Ved a vuestro señor. Si no me dais la casa cortarele he la cabeza». A esto García Sarmiento suplicaba: "Dadle esa casa y no moriré.» Pero su cuñado, Lope de Avalle, quc defcndía a Sobroso, contestó las seis veces que se repitió la escena: «Bien lo podeis matar, mas acá no entraredes.»

La condicta de Lope de Avalle es tanto más sorprendente por cuanto la figura de Pedro de Sotomayor estaba rodeada de un halo de terror, acompañado por el conocimiento que del secreto de sus acciones tenía y la rapidez de ejecución, producto de un perfecto conocimiento del terreno y buen servicio de espionaje. Así se puso en evidencia cuando el citado García de Sarmiento, con treinta hombres de a caballo, corría secretamente las ticrras de Sotomayor. Este les vigilaba por medio de espías para saber realmente lo que hacía y el número de hombres de que disponía en realidad. Desgraciadamente, la prudencia de algunos hombres de García Sarmiento y el temor que hacia su enemigo tenían no era compartida por el jefe, y cuando uno de sus peones le advirtió que había visto moverse a un hombrc entre la fraga, le contestó «que cada matorral le parecía un hombre». De nada sirvió la insistencia del criado, que le decía: «Señor, el conde de Camiña es muy falsa bestia.» Este selvicio de espionaje es lo que sin duda hizo que el conde de Camiña pudiese tomar parte principal en todas las acciones decisivas de la guerra hermandina y en la lucha nobiliaria que le siguió, principalmente contra el arzobispo compostelano y sus aliados. Este conocimiento de la situación estaba acompañado de una intuición para prevenirse del peligro basada en la desconfianza. Así pudo salir ileso de diversas asechanzas que se le tendieron. Como la del criado que con el pretexto de entregarle una carta iba dispuesto, mientras leyese la carta, a cortar las patas a su caballo. Verdad es que esta intuición y prevención no faltaban a otros nobles gallegos, acostumbrados a la lucha y a sus métodos. Tal es el caso de Martín de Barbeira, que cuando vio cómo Diego Andrade y otros iban a entrar en la nave de Ladrón de Guevara, corsario al servicio entonces del arzobispo de Santiago, observando «las sillas cubiertas de seda y los almohadones lo mismo, y los remadores todos gentiles hombres, y mui ataviados, no temian semilla de remadores... les dijo: $Y$ vosotros para donde is? Guardaos que no den con vosotros ahora en Vizcaya, y si vos entregan al rey grandes contas habeis de dar». Con estas palabras consiguió que no se embarcasen y cayeran en la trampa.

Faceta interesante de la fuente que comentamos son las cifras verdaderamente importantes de combatientes que indican, así como la movili- 
dad de personas y ejército tanto de día como de noche, la astucia que revelan los jefes al mismo tiempo que su conocimiento de la realidad, por ejemplo, el caso del paso del ejército que mandaba el conde de Camiña hacia Compostela para luchar contra los hermandinos aprovechando la marea baja cerca de Pontevedra; la audacia e incluso el humorismo que en momentos decisivos hacían gala los caudillos. Y en todo momento un desprecio absoluto por la muerte, considerada como cosa natural, producto de una profunda $f e$ religiosa. $Y$, por fin, no debemos olvidar, para completar las referencias sobre el asalto de las fortalezas, reparos de éstas y maneras de derrocarlas.

Combinando esta fuente con otras que conocemos, se puede llegar a un conocimiento de los móviles, procedimientos y consecuciones de un ejército nobiliar en Galicia bajomedieval. 